\title{
The prevalence and epidemiology of plasmid-mediated penicillin and tetracycline resistance among Neisseria gonorrhoeae isolates in Guangzhou, China, 2002-2012
}

Heping Zheng ${ }^{*}$, Xingzhong Wu, Jinmei Huang, Xiaolin Qin, Yaohua Xue, Weiying Zeng, Yinyuan Lan, Jiangli Ou, Sanmei Tang and Mingheng Fang

\begin{abstract}
Background: Gonococcal antimicrobial resistance is a global problem. Different resistance plasmids have emerged and spread among the isolates of Neisseria gonorrhoeae worldwide and in China. We conducted this study to monitor the plasmid-mediated penicillin and tetracycline resistance among N. gonorrhoeae isolates in Guangzhou from 2002 to 2012.

Methods: Consecutive isolates of $\mathrm{N}$. gonorrhoeae were collected from outpatients with gonorrhea attending the STD clinic in Guangdong Provincial Centre for Skin Diseases and STIs Control and Prevention. Penicillinase-producing N. gonorrhoeae (PPNG) isolates were analyzed by the paper acidometric method. Plasmid-mediated resistance to tetracycline in $N$. gonorrhoeae (TRNG) isolates was screened by the agar plate dilution method. Plasmid types were determined for TRNG and PPNG isolates using polymerase chain reaction $(\mathrm{PCR})$. Minimum inhibitory concentrations (MICs) to penicillin and tetracycline were detected by the agar plate dilution.
\end{abstract}

Results: Of 1378 consecutive N. gonorrhoeae isolates, 429 PPNG and 639 TRNG isolates were identified. The prevalence of PPNG, TRNG, and PPNG/TRNG increased from 18.3 to $47.1 \%\left(x^{2}=31.57, p<0.001\right)$, from 29.4 to $52.1 \%\left(x^{2}=16.28, p<0.001\right)$ and from 10.0 to $26.2 \%\left(x^{2}=10.46, p<0.001\right)$ between 2002 and 2012 , respectively. Genotyping of plasmids among PPNGs showed that the majority (93.7\%) of the isolates were the Asian type plasmids, while the African type plasmid emerged in 2008 and rapidly increased to $14.0 \%$ in $2012\left(x^{2}=25.03, p<0.001\right)$. For TRNGs, all 639 isolates carried the Dutch type plasmid. MICs of penicillin $G$ and tetracycline persisted at high levels and the $M C_{90}$ were 32 -fold higher than the resistant cutoff point over 11 years. The prevalence rates of penicillin- and tetracycline-resistant $\mathrm{N}$. gonorrhoeae varied from 90.9 to $91.1 \%$ and from 88.3 to $89.3 \%$ during 2002 to 2012, respectively.

Conclusions: Resistance to penicillin and tetracycline among N. gonorrhoeae isolates remained at high levels in Guangzhou. The Asian type PPNG continued to spread and Dutch type TRNG was still the dominant strain. The African type PPNG has emerged and is spreading rapidly.

Keywords: Neisseria gonorrhoeae, Antibiotic, Susceptibility, Plasmid, Genotype

\footnotetext{
* Correspondence: zhhpf@hotmail.com

Guangdong Provincial Centre for Skin Diseases and STIs Control and Prevention, Guangzhou 510091, China
}

\section{Biomed Central}

(c) 2015 Zheng et al. Open Access This article is distributed under the terms of the Creative Commons Attribution 4.0 International License (http://creativecommons.org/licenses/by/4.0/, which permits unrestricted use, distribution, and reproduction in any medium, provided you give appropriate credit to the original author(s) and the source, provide a link to the Creative Commons license, and indicate if changes were made. The Creative Commons Public Domain Dedication waiver (http://creativecommons.org/publicdomain/zero/1.0/) applies to the data made available in this article, unless otherwise stated. 


\section{Background}

Neisseria gonorrhoeae is the causative agent of gonorrhea, which is the second most prevalent bacterial sexually transmitted infection globally. The emergence and spread of antibiotic resistant $N$. gonorrhoeae has posed a challenge for successful control of gonorrhea worldwide. In recent decades, resistance developed to the antimicrobials previously recommended for treatment of gonorrhea, including penicillin, tetracyclines and fluoroquinolones [1-3]. Treatment failures regarding extended-spectrum cephalosporins such as oral cefixime and injectable ceftriaxone have been documented in Japan and several European countries, as well as resistance to spectinomycin, leading to the concern of no effective antibiotics for gonorrhea therapy in the near future [4-10].

Two types of $N$. gonorrhoeae resistance to penicillin and tetracycline are identified. They are chromosomally mediated acquisition of mutated genes or loci and plasmid-mediated resistance. Plasmid-mediated resistance to penicillin is due to the production of penicillinase [11]. Three main resistance plasmids (R-plasmids) are associated with the worldwide emergence of penicillinase-producing N. gonorrhoeae (PPNG). These main R-plasmids include an "Asian" R-plasmid of $7.4 \mathrm{~kb}$ in length, and its deletionderivatives "African" (5.6 kb) and "Toronto" (5.2 kb) [12]. Other types of penicillinase-producing plasmids have also been described in gonococci, e.g. Nimes, New Zealand, Australian and Johannesburg [12-15]. High level resistance to tetracycline (MIC $>16 \mathrm{mg} / \mathrm{L}$ ) in gonococci are mediated by a tet $\mathrm{M}$ determinant carried on a $25.2 \mathrm{MDa}$ conjugative plasmid [16]. The restriction endonuclease map of the 25.2 $\mathrm{MDa}$ conjugative plasmid from a tetracycline resistant $N$. gonorrhoeae (TRNG) strain imported from the United States has been found to differ from a map derived from a strain with the $24.5 \mathrm{MDa}$ conjugative plasmid isolated in the Netherlands [17]. These two types of tet $\mathrm{M}$ carrying conjugative plasmids were designated as "American" and "Dutch" types, respectively. Subsequent epidemiological studies have suggested a worldwide distribution for TRNG isolates $[18,19]$. Determination of plasmid-mediated penicillin and tetracycline resistance among $N$. gonorrhoeae is a useful epidemiologic tool for monitoring the movement or importation of isolates within a geographic region. However, the monitoring of these isolates in Asia is still limited.

Guangdong province in south China has over 100 million people, and one-quarter of them are migrant population. As a province that first opened to the world in 1980s, Guangdong experienced a rapid increase of STIs, including gonorrhea in the past three decades. In 2012, Guangdong reported 18,004 gonorrhea cases to the national disease reporting system accounting for $18.9 \%$ of the total cases identified in China [20]. Even though we have developed a gonorrhea reporting system, we still lack a comprehensive system that systematically monitors the resistance of $N$. gonorrhoeae. Our early survey showed that the prevalence of penicillin resistance had increased from 57.2 to $81.8 \%$ and PPNG had rapidly increased from 2 to $21 \%$ during 1996-2001 [21]. In order to monitor the change of penicillin- and tetracycline-resistant $N$. gonorrhoeae, and the change of PPNG and TRNG type, we conducted this study in Guangzhou, the capital city of Guangdong, from 2002 to 2012.

\section{Methods}

\section{Ethics statement}

The study has been approved by ethics committee of Guangdong Provincial Centre for Skin Diseases and STIs Control and Prevention. All patient data were anonymously reported, with no possibility of connecting the isolates to individual patients. In addition, the specimens used in this study were all clinical residual specimens, and no personal information was collected, so we did not need to ask for the participants to sign an informed consent. We have no longer have any contact with them.

\section{Bacterial isolates}

This study was conducted at Guangdong Provincial Center for Skin Disease and STIs Control and prevention. One thousand three hundred seventy eight consecutive isolates of $N$. gonorrhoeae were collected from patients diagnosed with gonorrhoea attending our STD clinic from 2000 to 2012. The isolates were cultured on Thayer-Martin agar and identified as $N$. gonorrhoeae based on colony morphology, Gram staining, oxidase test and carbohydrate degradation tests (all sugars were supplied by FLUKA company) as recommended by WHO [22]. The strains were preserved in freeze-dried skimmed milk and stored at $-70{ }^{\circ} \mathrm{C}$ until use. Antimicrobial susceptibility and plasmid-mediated resistance were analyzed in December of each year. All the isolates were revived successfully.

The WHO N. gonorrhoeae reference strains A, E, G and WHO-97QA3 were kindly provided by Dr Yin Yueping (National Center for STD control, China). PPNG control plasmids, pJD4 (Asian type), pJD5 (African type), and pJD7 (Toronto type) were kindly provided by Dr. J R Dillon (University of Saskatchewan, Canada). In addition, we used WHO-G with American type plasmid and WHO-97QA3 with Dutch type plasmid as the TRNG control plasmids.

\section{MIC detection and Interpretation of susceptibility}

All isolates were examined for susceptibility to penicillin G (SmithKline Beecham Limited) and tetracycline (Sigma-Aldrich Co. LLC.) by agar plate dilution method for MIC and antimicrobial susceptibilities were interpreted according to the criteria developed by WHO 
WPR Resistance Surveillance Programme guidelines [22]. For penicillin, isolates with $\mathrm{MICs} \geq 1.0 \mathrm{mg} / \mathrm{L}$ were classified as resistant, isolates with MICs of $0.6-0.50 \mathrm{mg} / \mathrm{L}$ as intermediate sensitive, and MICs $\leq 0.6 \mathrm{mg} / \mathrm{L}$ as sensitive. Isolates with $\mathrm{MICs} \leq 0.5 \mathrm{mg} / \mathrm{L}$ to tetracycline were classified as sensitive and isolates with MICs $>1 \mathrm{mg} / \mathrm{L}$ as resistant. WHO strains were used as quality controls; the MIC of penicillin to WHO A, E (PPNG) and $\mathrm{G}$ were $0.008 \mathrm{mg} / \mathrm{L}, \mathrm{MIC}>2 \mathrm{mg} / \mathrm{L}$ and $0.5 \mathrm{mg} / \mathrm{L}$, respectively and the MIC of tetracycline to WHO A, $\mathrm{E}$ and G (TRNG) were $0.25 \mathrm{mg} / \mathrm{L}, 1 \mathrm{mg} / \mathrm{L}$ and $32 \mathrm{mg} / \mathrm{L}$, respectively.

\section{Detection of PPNG and TRNG}

PPNG isolates were analyzed by the paper acidometric method [22]. WHO reference strains A and E were used as negative and positive controls, respectively. TRNG isolates were screened by the agar plate dilution method with the criteria of MIC $\geq 16 \mathrm{mg} / \mathrm{L}$ [23].

\section{Genotyping of PPNG and TRNG}

DNA extraction [21]: One hundred microliters of the $N$. gonorrhoeae isolates suspension (equivalent to McFarland No. 1 standard) in distilled water after 18 h' incubation were centrifuged at $14,000 \mathrm{~g}$ for $30 \mathrm{~min}$. The pellet was resuspended in $50 \mu \mathrm{L}$ of lysis buffer $(10 \mathrm{mmol} / \mathrm{L}$ Tris $\mathrm{HCl} \mathrm{pH} \mathrm{7.5,} 1 \mathrm{mmol} / \mathrm{L}$ EDTA pH 8.0, $0.1 \%$ Triton and $3000 \mathrm{U} / \mathrm{L}$ of proteinase $\mathrm{K}$ ) and then incubated at $100{ }^{\circ} \mathrm{C}$ for $15 \mathrm{~min}$. The supernatant were then used as a template for PCR amplification.

The Asian (7426 bp), African (5599 bp) and Toronto (5154 bp) type plasmids of PPNGs were differentiated by the PCR assays [24]. Four pairs of PCR primers were used for TEM-1 gene. The tetM gene of TRNG was amplified to identify American (AR) and Dutch (DR) variant [25]. A universal forward primer (UF) that hybridizes with both variants was combined with reverse primers specific to each variant (AR and $D R$ ). The primer sequences were derived from the sequences of pOZ100 (UF, AR) and pOZ101 (DR). All primers described in Table 1 were synthesized by Invitrogen Bio. Co. (Shanghai, China).
Four microliters of each extracted DNA from either reference or clinical isolates were used for amplification in a $50 \mu \mathrm{L}$ solution containing: $200 \mu \mathrm{mol} / \mathrm{L}$ (each) dATP, dCTP, dGTP and dTTP; $50 \mu \mathrm{mol} / \mathrm{L} \mathrm{KCl} ; 10 \mathrm{mM}$ Tris $\mathrm{HCl}(\mathrm{pH} 8.4) ; 1.5 \mu \mathrm{mol} / \mathrm{L} \mathrm{MgCl}_{2} ; 0.5 \mu \mathrm{mol} / \mathrm{L}$ of each oligonucleotide primer and $1.25 \mathrm{U}$ of Taq DNA polymerase (Takara, Japan). Thirty-five cycles of amplification were performed in a thermocycler (Perkin-Elmer 9600). Each cycle consisted of $30 \mathrm{~s}$ of denaturation at $95{ }^{\circ} \mathrm{C}, 30 \mathrm{~s}$ of annealing at $55{ }^{\circ} \mathrm{C}$ and $1 \mathrm{~min}$ of extension at $72{ }^{\circ} \mathrm{C}$. PCR products were analyzed by electrophoresis in $1 \% \mathrm{w} / v$ agarose and visualized by ultraviolet fluorescence after ethidium bromide staining.

\section{Statistical analysis}

In this study, SPSS 18.0 (IBM) was used for all statistical analyses. Descriptive analyses were conducted to determine the distribution of genotype and resistance. In addition, we also performed trend analysis to test the trend of resistance during the study period.

\section{Results}

\section{PPNG and TRNG prevalence}

Of the 1378 consecutive gonococci isolated from 2002 to 2012, 429 PPNG isolates were identified by paper acidimetric method and 639 TRNG isolates were identified by agar plate dilution method. The prevalence of PPNG, TRNG, and PPNG/TRNG increased from 18.3 to $47.1 \%\left(\chi^{2}=31.570, p<0.001\right)$, from 29.4 to $52.1 \%\left(\chi^{2}=\right.$ $16.282, p<0.001)$ and from 10.0 to $26.2 \%\left(\chi^{2}=10.462\right.$, $p<0.01$ ) during the study period, respectively (Table 2 ).

\section{TEM-1 and tetM gene genotyping}

The identified PPNGs and TRNGs were further genotyped according to the lengths of TEM- 1 and tet $\mathrm{M}$ PCR production (Table 2). The results showed that Asian type plasmids dominated the $N$. gonorrhoeae isolates during the study period. However, African type plasmids emerged in $2008(1.3 \%)$ and quickly increased to $14.0 \%$ in $2012\left(\chi^{2}=25.029, p<0.001\right)$. In addition, one Toronto type was identified in 2012. All of 639 TRNGs carried the Dutch type plasmids.

Table 1 Primers used for the detection of TEM-1 and tetM in N. gonorrhoeae

\begin{tabular}{lllll}
\hline Gene & Primer & Direction & Primer sequencea $\left(5^{\prime}-3^{\prime}\right)$ & Reference \\
\hline TEM-1 & BL1 & Forward & ${ }^{1545}$ TACTCAATCGGTAATTGGCT $^{1564}$ & Palmer HM et al. ${ }^{24, a}$ \\
& BL2 & Forward & ${ }^{3606}$ CACCTATAAATCTCGCAAGC $^{3625}$ & \\
& BL3 & Reverse & ${ }^{4564}$ CCATAGTGTTGAGTATTGCGAA $^{4543}$ & \\
tetM & BL4 & Reverse & ${ }^{6528}$ TCATTCGTGCGTTCTAGGA ${ }^{6510}$ & Turner A et al. ${ }^{25}$ \\
& UF & Forward & ${ }^{825}$ CTCGAACAAGAGGAAAGC $^{842}$ & \\
& AR & Reverse & ${ }^{1602}$ GCATCCACTTCCCAAC $^{1586}$ & \\
\hline
\end{tabular}

Positions are based on the Asian plasmid, Genbank accession number U20374 
Table 2 The distribution of types of TEM-1 and tetM among PPNG and TRNG isolates 2002-2012

\begin{tabular}{|c|c|c|c|c|c|c|c|c|c|}
\hline \multirow[t]{3}{*}{ Year } & \multirow{3}{*}{$\begin{array}{l}\text { No.of } \\
\text { isolates }\end{array}$} & \multicolumn{4}{|l|}{ PPNG (\%) } & \multicolumn{3}{|l|}{ TRNG (\%) } & \multirow[t]{3}{*}{ PPNG/TRNG (\% } \\
\hline & & \multirow{2}{*}{$\begin{array}{l}\text { No. of } \\
\text { isolates }\end{array}$} & \multicolumn{3}{|c|}{ Type of TEM-1 } & \multirow{2}{*}{$\begin{array}{l}\text { No. of } \\
\text { isolates }\end{array}$} & \multicolumn{2}{|c|}{ Type of tetM } & \\
\hline & & & Asain & African & Toronto & & Dutch & American & \\
\hline 2002 & 180 & $33(18.3)$ & $33(100)$ & 0 & 0 & $53(29.4)$ & $53(100)$ & 0 & $18(10.0)$ \\
\hline 2003 & 115 & $31(27.0)$ & $31(100)$ & 0 & 0 & $50(43.5)$ & $50(100)$ & 0 & $20(17.4)$ \\
\hline 2004 & 90 & $21(23.3)$ & $21(100)$ & 0 & 0 & $44(48.9)$ & $44(100)$ & 0 & $8(8.9)$ \\
\hline 2005 & 76 & $18(23.7)$ & $18(100)$ & 0 & 0 & $35(46.1)$ & $35(100)$ & 0 & $14(20)$ \\
\hline 2006 & 104 & $27(26.0)$ & $27(100)$ & 0 & 0 & $40(38.5)$ & $40(100)$ & 0 & $19(20.2)$ \\
\hline 2007 & 95 & $30(31.5)$ & $30(100)$ & 0 & 0 & $41(43.6)$ & $41(100)$ & 0 & 29 (23.6) \\
\hline 2008 & 183 & 75 (42.0) & 74 (99.7) & $1(1.3)$ & 0 & $108(59.0)$ & $108(100)$ & 0 & $48(26.2)$ \\
\hline 2009 & 151 & $45(29.8)$ & $43(96.6)$ & $2(4.4)$ & 0 & $85(56.3)$ & $85(100)$ & 0 & $25(16.7)$ \\
\hline 2010 & 136 & $51(37.5)$ & $44(87.3)$ & $7(13.7)$ & 0 & $67(49.3)$ & $67(100)$ & 0 & $33(24.3)$ \\
\hline 2011 & 127 & $41(32.3)$ & $33(81.5)$ & $8(19.5)$ & 0 & $53(41.7)$ & $53(100)$ & 0 & $15(11.8)$ \\
\hline 2012 & 121 & $57(47.1)$ & $48(84.2)$ & $8(14.0)$ & $1(1.8)$ & $63(52.1)$ & $63(100)$ & 0 & $32(26.2)$ \\
\hline Total & 1378 & $429(31.1)$ & 402 (93.7) & $18(6.1)$ & $1(0.2)$ & 639 (46.4) & 639 (100) & 0 & 261 (18.9) \\
\hline
\end{tabular}

MICs of penicillin $\mathrm{G}$ and tetracycline

The distribution of $\mathrm{MIC}_{50}$ and $\mathrm{MIC}_{90}$ of penicillin $\mathrm{G}$ and tetracycline from the 1378 consecutive isolates are summarized in Table 3. MICs of penicillin G and tetracycline persisted at high level and the $\mathrm{MIC}_{90 \mathrm{~s}}$ were 32-fold higher than the resistant cutoff point over 11 years. The penicillin-resistant prevalence was maintained at high levels (90.9\% in 2002 to $91.1 \%$ in 2012) as were for tetracycline resistance $(88.3 \%$ in 2002 to $89.3 \%$ in 2012).

\section{Discussion}

Globally, the increasing proportion of PPNG and TRNG has become a serious concern. PPNG was initially found in clinical isolates in Thailand and in the United Kingdom in 1976 [11, 26], and TRNG was firstly found in the
United States in 1985 [27]. Since then, more PPNG and TRNG were identified and reported worldwide. Epidemiological studies showed that countries in East Asia have significantly different distributions of PPNG, for example, 55 \% in India, 33 \% in Pakistan, 86 \% in Bhutan in 2007-11 [28], and 79.3\% in Thailand in 2005-7 [29]. In Japan, among the $719 \mathrm{~N}$. gonorrhoeae isolates isolated from January 2000 to December 2008, only 10 PPNG isolates $(1.4 \%)$ were found [30]. In Nanjing, China, PPNG and TRNG were reported to increase from 8.0 to $44.4 \%$ and from 1.8 to $32.8 \%$ respectively during 1999-2006 [31]. A high PPNG prevalence of 51.3 and $49.2 \%$ were maintained while a TRNG increased from 19.6 to $42.1 \%$ was observed in the neighboring city of Shanghai over two time periods, 2004-2005 and 2008-2011 [32]. In Guangzhou, the prevalence of PPNG increased yearly

Table 3 Susceptibilities of N. gonorrhoeae to Penicillin G and Tetracycline 2002-2012 (mg/L)

\begin{tabular}{|c|c|c|c|c|c|c|c|c|c|c|c|c|}
\hline \multirow[t]{2}{*}{ Year } & \multirow{2}{*}{$\begin{array}{l}\text { No.of } \\
\text { isolates }\end{array}$} & \multicolumn{6}{|c|}{ Penicillin $G^{a}$} & \multicolumn{5}{|c|}{ Tetracycline } \\
\hline & & $\mathrm{MIC}_{50}$ & $\mathrm{MIC}_{90}$ & MIC range & S (\%) & | (\%) & R (\%) & $\mathrm{MIC}_{50}$ & $\mathrm{MIC}_{90}$ & MIC range & S (\%) & R (\%) \\
\hline 2002 & 180 & 4 & $>32$ & $0.03->32$ & $1(0.6)$ & $15(8.3)$ & $164(91.1)$ & 2 & $>16$ & $0.125->16$ & $21(11.7)$ & 159 (88.3) \\
\hline 2003 & 115 & 16 & $>32$ & $0.06->32$ & $0(0.0)$ & $3(2.6)$ & $112(97.4)$ & 2 & $>16$ & $0.5->16$ & $23(20.0)$ & $92(80.0)$ \\
\hline 2004 & 90 & 4 & $>32$ & $0.125->32$ & $0(0.0)$ & $8(8.9)$ & $82(91.1)$ & 4 & $>16$ & $0.5->16$ & $12(13.3)$ & $78(86.7)$ \\
\hline 2005 & 76 & 16 & $>32$ & $0.25->32$ & $0(0.0)$ & $5(6.6)$ & 71 (93.4) & 4 & 64 & $<0.5->64$ & 15 (19.7) & $64(84.3)$ \\
\hline 2006 & 104 & 8 & $>32$ & $>32-0.125$ & $0(0.0)$ & $5(4.8)$ & $99(95.2)$ & 8 & 16 & $0.5->64$ & $20(19.2)$ & $84(80.8)$ \\
\hline 2007 & 95 & 8 & $>32$ & $0.06->32$ & $4(4.2)$ & $9(9.5)$ & $82(86.3)$ & 32 & $>32$ & $<0.5->32$ & 17 (17.9) & $78(82.1)$ \\
\hline 2008 & 183 & 8 & $>32$ & $<0.06->32$ & $2(1.1)$ & $16(8.7)$ & $165(90.2)$ & 16 & $>32$ & $<0.25->32$ & $12(6.6)$ & $171(93.4)$ \\
\hline 2009 & 151 & 1 & $>32$ & $0.125->32$ & $1(0.7)$ & $44(29.1)$ & $106(70.1)$ & 32 & $>32$ & $0.25->32$ & $13(8.7)$ & 138 (91.4) \\
\hline 2010 & 136 & 2 & $>32$ & $0.125->32$ & $1(0.7)$ & 55 (40.4) & $80(58.9)$ & 8 & $>32$ & $<0.25->32$ & $17(12.5)$ & 119 (87.5) \\
\hline 2011 & 127 & 2 & $>32$ & $<0.03->32$ & $1(0.8)$ & $22(17.3)$ & 104 (81.9) & 4 & $>32$ & $<0.125->32$ & $0(0.0)$ & $127(100)$ \\
\hline 2012 & 121 & 4 & $>32$ & $0.25->32$ & 0 & $11(9.1)$ & $110(90.9)$ & 4 & $>32$ & $0.125->32$ & $13(10.7)$ & 108 (89.3) \\
\hline
\end{tabular}

${ }^{\mathrm{a}} \mathrm{MIC} \mathrm{mg} / \mathrm{L}, \mathrm{S}$ sensitivity, I intermediate sensitivity, $R$ resistance 
from 2 to $21.8 \%$ and TRNG from 1.5 to $27.2 \%$ during 1996-2001 [21]. In the present study, continuing increases were found from 18.3 to $47.1 \%$ for PPNG and from 29.4 to $52.1 \%$ for TRNG in 2002-2012.

In this study, we detected the Asian, African, and Toronto plasmids among our clinical isolates. The majority (93.7\%) of the consecutive PPNGs were genotyped as the Asian plasmid, which was similar to the results in Nanjing, China, in 1999-2006 [31]. However, the African type plasmid which was found in 2008 rapidly increased to $19.5 \%$ in 2011 and $14.0 \%$ in 2012 ; one Toronto type was first isolated in 2012. In contrast, different distributions of R-plasmid types were reported in Bangkok, Thailand, with $82.3 \%$ African, $8.3 \%$ Asian and $9.3 \%$ Toronto types in 2005-7 [29], $100 \%$ African type in Bangladesh in 2012 [33], $50 \%$ African, $40 \%$ Asian and $10 \%$ Toronto types in Japan during 2000-8 [30] and $35.2 \%$ African and $44.4 \%$ Toronto types in South Africa in 2008 [34]. Our results showed a different trend of R-plasmid types in Guangzhou from 2002 to 2012. It is possible that the change over time is the result of more and more people from Africa and eastern Asian migrating and doing commercial business in Guangzhou.

High-level tetracycline resistance in $N$. gonorrhoeae is mediated by the tetM determinant. During 1988 to 1995, 518 isolates of TRNG isolated in the United Kingdom but originating from infections acquired in 39 countries worldwide were collected and typed by the tetM PCR assay. The results showed various distribution of tetM types, $98.3 \%$ (59/60) American and $0.7 \%$ (1/60) Dutch type in Africa, $40 \%(4 / 10)$ American and $60 \%(6 / 10)$ Dutch type in North, Central and South America, $64.3 \%$ (36/56) American and $35.7 \%$ (20/56) Dutch type in the Caribbean, $82 \%$ (248/306) American and $18 \%$ (58/306) Dutch type in Europe, and 100 \% (35/35) Dutch type in the Far East [25]. In addition, Canada also reported that Dutch type tetM gene predominated (79.35\%) from 1986 to 1997 [35]. In recent years, $24 \%$ (37/154) Dutch and $76 \%(117 / 154)$ American type were found in South Africa in 2008 [34]. In Bangladesh,98.7 \% (377/382) Dutch and $1.3 \%$ (5/382) American type of TRNG were reported in 2012 [33]. However, in our study, we only found the Dutch type TRNG in the past 11 years. Similar results were reported in Nanjing in 2001-6 [31], Shanghai in 2004-5 [36] and Chengdu in 1999-2002 [37]. This finding further confirmed that Dutch type TRNG was dominant in China.

Penicillin and tetracycline have not been used as the first- or second-line therapeutic agents to treat gonorrhea for many years. During 2002-2012, penicillin and tetracycline had maintained high MICs in Guangzhou; this further supports the decision not to use penicillin and tetracycline to treat gonorrhoea. $\mathrm{MIC}_{90 \mathrm{~s}}$ of penicillin
$\mathrm{G}$ and tetracycline already reached at least 32-fold of the resistant cutoff point and were largely in accordance with previous surveys conducted in Southeast Asia. The rates of resistance to penicillin and tetracycline were much higher than the findings of studies conducted in Pakistan $(86.8 \%$ penicillin resistance and $77.6 \%$ tetracycline resistance in 2009) [38], India (68 \% penicillin and $55.4 \%$ tetracycline resistance) and Vietnam (48\% penicillin and $82 \%$ tetracycline resistance) in 2011 [39]. These rates indicated that South China might have even bigger challenges regarding resistant $N$. gonorrhoeae. In view of increasing resistance to cephalosporins such a cefixime and ceftriaxone [40], it is recommended that all cases of gonorrhea should also be covered for concomitant chlamydial infection as dual antibiotics might delay the onset of cephalosporin resistance [41]. Macrolide resistances $N$. gonorrhoeae is relatively low in many countries such as United States (0.04 \%) [42]: and United Kingdom (1.6\% in England and Wales) [43] although cases have been reported [42, 44, 45]. In such cases, the choice for covering chlamydial infection should be a macrolide such as azithromycin rather than tetracycline such as doxycycline because of high rates of tetracycline resistance worldwide as well as in China. Furthermore, there is in vitro evidence of synergy between azithromycin and cephalosporin as well as more effective eradication for pharyngeal gonorrhea [46].

\section{Conclusions}

In summary, the levels of resistance to penicillin and tetracycline were consistently high in Guangzhou. PPNG and TRNG have rapidly increased, in which, the Asian type PPNG has continued to further spread and the Dutch type TRNG is still the dominant strain in Guangzhou. In addition, the African type PPNG has increased in recent years, while Toronto type had emerged in 2012.

\section{Abbreviations}

N. gonorrhoeae: Neisseria gonorrhoeae; MICs: Minimum inhibitory concentrations; PPNG: Penicillinase producing N. gonorrhoeae; TRNG: Tetracycline resistant N. gonorrhoeae; STD: Sexually Transmitted Disease; STls: Sexually Transmitted Infections.

\section{Competing interest}

The authors declare that they have no competing interests.

\section{Authors' contributions}

$X W$ and Jh carried out the MIC detection. XQ, YX and $Y L$ carried out the molecular biology studies and genotyping. WZ, JO, ST and MF participated in the collecting of isolates and part of MIC detection. $\mathrm{HZ}$ was PI of the NG resistance surveillance program, responsible for designing, supervision, coordination or data analysis and manuscript writing. All authors read and approved the final manuscript.

Authors' information

Not applicable 


\section{Acknowledgments}

The authors acknowledge Dr. Beng Tin Goh for proof reading this manuscript. This work has been funded by Medical Science Funds of Guangdong Provincial Bureau of Public Health (no. B2010049) and National Gonococcal Resistance Research surveillance programme.

Received: 9 December 2014 Accepted: 24 September 2015 Published online: 09 October 2015

\section{References}

1. Tapsall JW, Ndowa F, Lewis DA, Unemo M. Meeting the public health challenge of multidrug- and extensively drug-resistant Neisseria gonorrhoeae. Expert Rev Anti Infect Ther. 2009;7:821-34.

2. Workowski KA, Berman SM, Douglas JM. Emerging antimicrobial resistance in Neisseria gonorrhoeae: urgent need to strengthen prevention strategies. Ann Intern Med. 2008;148:606-13.

3. Tapsall J. Antibiotic resistance in Neisseria gonorrhoeae is diminishing available treatment options for gonorrhea: some possible remedies. Expert Rev Anti Infect Ther. 2006;4:619-28.

4. Yokoi S, Deguchi T, Ozawa T, Yasuda M, Ito S, Kubota Y, et al. Threat to cefixime treatment for gonorrhea. Emerg Infect Dis. 2007;13:1275-7.

5. Ison CA, Hussey J, Sankar KN, Evans J, Alexander S. Gonorrhoea treatment failures to cefixime and azithromycin in England, 2010. Euro Surveill. 2011;16:19833

6. Unemo M, Golparian D, Syversen G, Vestrheim DF, Moi H. Two cases of verified clinical failures using internationally recommended first line cefixime for gonorrhoea treatment, Norway, 2010. Euro Surveill. 2010;15:19721.

7. Cámara J, Serra J, Ayats J, Bastida T, Carnicer-Pont D, Andreu A, et al. Molecular characterization of two high-level ceftriaxone-resistant Neisseria gonorrhoeae isolates detected in Catalonia, Spain. J Antimicrob Chemother. 2012:67:1858-60.

8. Unemo M, Golparian D, Nicholas R, Ohnishi M, Gallay A, Sednaoui P, et al. High-level cefixime- and ceftriaxone-resistant Neisseria gonorrhoeae in France: novel penA mosaic allele in a successful international clone causes treatment failure. Antimicrob Agents Chemother. 2012;56:1273-80.

9. Ohnishi M, Saika T, Hoshina S, Iwasaku K, Nakayama S, Watanabe H, et al. Ceftriaxone-resistant Neisseria gonorrhoeae, Japan. Emerg Infect Dis. 2011;17:148-9.

10. Boslego JW, Tramont EC, Takafuji ET, et al. Effect of spectinomycin use on the prevalence of spectinomycin-resistant and penicillinase-producing Neisseria gonorrhoeae. N Engl J Med. 1987:317:272-8.

11. Ashford WR, Golash R, Hemming V. Penicillinase-producing Neisseria gonorrhoeae. Lancet. 1976;2:657-8.

12. Dillon JA, Yeung KH. Beta-lactamase plasmids and chromosomally mediated antibiotic resistance in pathogenic Neisseria species. Clin Microbiol Rev. 1989;2(Suppl):S125-33.

13. Unemo M, Shafer WM. Antimicrobial resistance in Neisseria gonorrhoeae in the 21st century: past, evolution and future. Clin Microbiol Rev. 2014;27:587-613.

14. Trembizki E, Buckley C, Lawrence A, Lahra M, Whiley D. On behalf of the GRAND study investigators: Characterisation of a novel Neisseria gonorrhoeae penicillinase-producing plasmid, Australia 2012. Antimicrob Agents Chemother. 2014;58:4984-5.

15. Müller EE, Fayemiwo SA, Lewis DA. Characterization of a novel betalactamase-producing plasmid in Neisseria gonorrhoeae: sequence analysis and molecular typing of host gonococci. J Antimicrob Chemother. 2011:66:1514-7.

16. Morse SA, Johnson SR, Biddle JW, Roberts MC. High-level tetracycline resistance in Neisseria gonorrhoeae is result of acquisition of streptococcal tetM determinant. Antimicrob Agents Chemother. 1986;30:664-70

17. Gascoyne DM, Heritage J, Hawkey PM, Turner A, van Klingeren B. Molecular evolution of tetracycline-resistance plasmids carrying tetM found in Neisseria gonorrhoeae from different countries. J Antimicrob Chemother. 1991;28:173-83.

18. Gascoyne-Binzi DM, Hawkey PM, Heritage J, Turner A, Nadarajah M. Worldwide distribution of high level tetracycline-resistant Neisseria gonorrhoeae. Genitourin Med. 1992:68:277-8.

19. Turner A, Gough KR, Jephcott AE, McClean AN. Importation into the UK of a strain of Neisseria gonorrhoeae resistant to penicillin, ciprofloxacin and tetracycline. Genitourin Med. 1995;71:331-2.
20. NCSTD. Epidemiologic reports of syphilis and gonorrheae case reports in China. http://www.ncstdc.org/upfiles/201303/20130319152506703.pdf, accessed on Jan 2013

21. Zheng HP, Cao WL, Wu XZ, Yang LG. Antimicrobial susceptibility of Neisseria gonorrhoeae strains isolated in Guangzhou, China, 1996-2001. Sex Transm Inf. 2003;79:399-402.

22. World Health Organization. Sensitivity testing of Neisseria gonorrhoeae: Methodologies for use by participants in the WHO western Pacific regional surveillance programme. In: WHO/WPR Regional Antimicrobial Surveillance Working Group Meeting Proceedings. 1992.

23. Van Dyck E, Piot P, Meheus A. Bench-level laboratory manual for sexually transmitted diseases, VDT/89.443. Geneva: World Health Organization; 1989

24. Palmer HM, Leeming JP, Turner A. A multiplex polymerase chain reaction to differentiate ß-lactamase plasmids of Neisseria gonorrhoeae. Antimicrob Chemother. 2000;45:777-82.

25. Turner A, Gough KR, Leeming JP. Molecular epidemiology of tetM genes in Neisseria gonorrhoeae. Sex Transm Infect. 1999;75:60-6.

26. Percival A, Rowlands J, Corkill JE. Penicillinase-producing gonococci in Liverpool. Lancet. 1976;2:1379-82.

27. Centers for Disease Control (CDC). Tetracycline-resistant Neisseria gonorrhoeae-Georgia, Pennsylvania. New Hampshire. MMWR. 1985;34:563-4. 569-70.

28. Sethi S, Golparian D, Bala M, Dorji D, Ibrahim M, Jabeen K, et al. Antimicrobial susceptibility and genetic characteristics of Neisseria gonorrhoeae isolates from India, Pakistan and Bhutan in 2007-2011. BMC Infect Dis. 2013;13:35.

29. Nakayama S, Tribuddharat C, Prombhul S, Shimuta K, Shimuta K, Srifuengfung $S$, et al. Molecular Analyses of TEM Genes and Their Corresponding Penicillinase-Producing Neisseria gonorrhoeae Isolates in Bangkok, Thailand. Antimicrob Agents Chemother. 2012;56:916-20.

30. Ohnishi M, Ono E, Shimuta K, Watanabe H, Okamura N. Identification of TEM-135 -Lactamase in Penicillinase-Producing Neisseria gonorrhoeae Strains in Japan. Antimicrob Agents Chemother. 2010;54:3021-3.

31. Su X, Jiang F, Qimuge, Dai X, Sun H, Ye S, et al. Surveillance of Antimicrobia Susceptibilities in Neisseria gonorrhoeae in Nanjing, China, 1999-2006. Sex Transm Dis. 2007:34:995-9.

32. Trecker MA, Waldner C, Jolly A, Liao M, Gu W, Dillon JA, et al. Behavioral and socioeconomic risk factors associated with probable resistance to ceftriaxone and resistance to penicillin and tetracycline in Neisseria gonorrhoeae in Shanghai. PLoS One. 2014;9:e89458.

33. Alam MA, Chowdhury ZU, Chowdhury AH, Rahman M. Epidemic plasmids in Neisseria gonorrhoeae isolated from high-risk population in Bangladesh. Mymensingh Med J. 2012;21:220-5.

34. Fayemiwo SA, Müller EE, Gumede L, Lewis DA. Plasmid-mediated penicillin and tetracycline resistance among Neisseria gonorrhoeae isolates in South Africa: prevalence, detection and typing using a novel molecular assay. Sex Transm Dis. 2011:38:329-33.

35. Greco V, Ng LK, Catana R, Li H, Dillon JA. Molecular epidemiology of Neisseria gonorrhoeae isolates with plasmid-mediated tetracycline resistance in Canada: Temporal and geographical trends (1986-1997). Microb Drug Resist. 2003;9:353-60.

36. Yang Y, Wu L, Zhang CG, Gu WM. The susceptibility of Neisseria gonorrhoeae isolated in Shanghai and resistance mechanism. Chin J Lab Med. 2009;32:1173-5.

37. Yong G, Yang X, Tan J, Liao WS, Yu LC, Yang JQ, et al. Typing Plasmid of high-level tetracycline resistant Neisseria gonorrhoeae by PCR. Chin J Microbiol Immunol. 2006:26:189-90.

38. Jabeen K, Nizamuddin S, Irfan S, Khan E, Malik F, Zafar A, et al. Increasing trend of resistance to penicillin, tetracycline, and fluoroquinolone resistance in Neisseria gonorrhoeae from Pakistan (1992-2009). J Trop Med. 2011. doi:10.1155/2011/960501

39. Olsen B, Pham TL, Golparian D, Johansson E, Tran HK, Unemo M, et al. Antimicrobial susceptibility and genetic characteristics of Neisseria gonorrhoeae isolates from Vietnam, 2011. BMC Infect Dis. 2013;13:40

40. Ison CA, Town K, Obi C, Chisholm S, Hughes G, Livermore DM, et al. Decreased susceptibility to cephalosporins among gonococci: data from the Gonococcal Resistance to Antimicrobials Surveillance Programme (GRASP) in England and Wales, 2007-2011. Lancet Infect Dis. 2013;13:762-8

41. Unemo M, Nicholas RA. Emergence of multidrug-resistant, extensively drugresistant and untreatable gonorrhoea. Future Microbiol. 2012;7:1401-22. 
42. Centers for Disease Control and Prevention (CDC). Neisseria gonorrhoeae with reduced susceptibility to azithromycin-San Diego County, California, 2009. MMWR Morb Mortal Wkly Rep. 2011;60:579-81.

43. Chisholm S, Town K, Furegato M, Were J, Simms I, Mohammed H, et al. GRASP 2013 Report. The Gonococcal Resistance to Antimicrobials Surveillance Programme (England and Wales) Public Health England October 2014. www.gov.uk/government/uploads/system/uploads/ attachment_data/file/368477/GRASP_Report_2013.pdf

44. Palmer HM, Young H, Winter A, Dave J. Emergence and spread of azithromycin-resistant Neisseria gonorrhoeae in Scotland. J Antimicrob Chemother. 2008;62:490-4.

45. Katz AR, Komeya AY, Soge OO, Kiaha MI, Lee MV, Wasserman GM, et al. Neisseria gonorrhoeae with high-level resistance to azithromycin: case report of the first isolate identified in the United States. Clin Infect Dis. 2012;54:841-3.

46. Furuya R, Nakayama H, Kanayama A, Saika T, lyoda T, Tatewaki M, et al. In vitro synergistic effects of double combinations of beta-lactams and azithromycin. J Infect Chemother. 2006;12:172-6.

\section{Submit your next manuscript to BioMed Central and take full advantage of:}

- Convenient online submission

- Thorough peer review

- No space constraints or color figure charges

- Immediate publication on acceptance

- Inclusion in PubMed, CAS, Scopus and Google Scholar

- Research which is freely available for redistribution 